\title{
Effect of Placing Double-lumen Irrigation-suction Tube on Spontaneous Closure of Anastomotic Leakage Following Rectal Cancer Surgery
}

\section{Weliang Tian}

Jinling Hospital

Ming Huang

Nanjing Jiangning Hospital

Xin Xu

Nanjing Jiangning Hospital

Zheng Yao ( $\nabla$ dr_yaozheng@163.com )

Nanjing Jiangning Hospital

Risheng Zhao

Nanjing Jiangning Hospital

\section{Research Article}

Keywords: rectal cancer surgery, anastomotic leakage, double-lumen irrigation-suction tube, spontaneous closure, retrospective cohort study

Posted Date: November 10th, 2021

DOl: https://doi.org/10.21203/rs.3.rs-969284/v1

License: (1) This work is licensed under a Creative Commons Attribution 4.0 International License. Read Full License 


\section{Abstract}

Purpose: This study aimed to explore the effect of placement of double-lumen irrigation-suction tubes (DLIST) on the spontaneous closure of anastomotic leakages (AL) after rectal cancer surgery.

Methods: The study was performed at two centers which was managed by the same chief. The treatment in the two center were same. From January 2011 to June 2020, patients with postoperative AL after rectal cancer surgery were eligible. Patients were divided into a passive drainage (PD) group and a DLIST group according to whether the PD,placed during the rectal cancer surgery, had been replaced with the DLIST. The effect of DLIST on the AL was evaluated.

Result: There were 76 patients in the DLIST group and 52 in the PD group. The DLIST group was more inclined to achieve spontaneous closure of $\mathrm{AL}(\mathrm{HR}=3.048 ; 95 \% \mathrm{Cl}$ : 1.787-5.197; $\mathrm{P}<0.001)$. Both length of stay and costs of the treatment in the DLIST group were lower (54 [41.25-117] days vs. 112 [66.75$127.75]$ days, $P=0.005$; and $\$ 18,721$ [\$14,982-44,960] vs. $\$ 40,840[\$ 20,932-50,529], P<0.001)$.

Conclusion: Placement of DLIST is an effective method for treating AL following rectal cancer surgery. Compared with PD, the cost of DLIST in the treatment of AL is lower and the length of stay is shorter.

\section{Introduction}

Anastomotic leakage $(\mathrm{AL})$ is one of the most severe complications after rectal cancer surgery[1]. The incidence of rectal AL ranges from 5-28\%[2-6]. The spontaneous closure rate varied in different studies[7-10].

More than half of the patients end up with a permanent stoma after the standard treatment $[7,8]$. In the past 10 years, two novel methods for the treatment of $A L$ have been proposed $[9,10]$. In few selected patients, the two methods,transanal drainage and endoscopic vacuum-assisted closure, elevated the spontaneous closure rate as high as $90 \%[9,10]$. However, in a recent study involving more patients, it was shown that the 2-year spontaneous closure rate using the two new methods was only about $50 \%[11]$. In short, treatment aimed at spontaneous closure of rectal AL is still relatively difficult and worthy of exploration.

A double-lumen irrigation-suction tube (DLSIT) was introduced in our previous studies[12,13]. It has been proven that DLIST is more superior for source control compared with passive drainage. Our recent multicenter research showed that placing DLISTs during rectal surgery might promote the spontaneous closure of AL[12]. However, in clinical work, it was discovered that intraoperative placement of an active drainage device similar to a DLIST was rare. When AL occurred, effective irrigation and drainage were not established, and there was often a pus cavity around the passive drainage tube. The two centers involved in this study treated a large number of rectal AL patients every year. In recent years, our center tried to replace the passive drainage tube with DLIST in patients with rectal AL after admission to our centers. In 
the present study, we explored the effect of replacement of PDs with DLISTs on the spontaneous closure and provide a benchmark for future treatment.

\section{Method And Material}

This was a retrospective cohort study performed at two tertiary hospitals. Every year, hundreds of patients with refractory intestinal fistula transferred to the two centers, which was managed by the same chief. The treatment in the two center were same. The ethics committee of Jinling Hospital and Jiangning hospital approved the retrospective data collection; all subjects provided signed informed consent. All methods were carried out in accordance with relevant guidelines and regulations.

DLIST was introduced in our previous study[13]. In brief, the DLIST consists of an irrigation catheter, a suction catheter, and an end-closed supporting pipe (made by a $24 \mathrm{Fr}$ silica gel drainage tube). Saline was continuously irrigated through the irrigation catheter at $100-150 \mathrm{~mL} / \mathrm{h}$, along with drainage from the suction catheter under continuous negative pressure of 150-200 mmbar (Figure 1).

\subsection{Study design}

From January 2011 to June 2020, patients who transferred to either of the two centers with postoperative AL after rectal cancer surgery were eligible. The exclusion criteria included 1) patients with evidence of tumor metastasis and 2) patients receiving an emergency surgery due to the AL after admission.

According to whether or not the passive drainage placed during the rectal cancer surgery was replaced with the DLIST, patients were divided into a passive drainage (PD) group and a double-lumen irrigationsuction tube (DLIST) group (Figure 2). The effect of DLIST on the AL was evaluated.

\subsection{Follow up}

Patients were planed to received a definitive surgery at least after three months after infection control and improvement of nutritional status. During the period before definitive surgery, there were patients with spontaneous closure. All the patients were followed up to spontaneous closure or to discharge after definitive surgery. The primary outcome was the spontaneous closure of AL. The secondary outcomes included the hospital length of stay (LOS) and hospitalization expenses.

Spontaneous closure was confirmed only after colonography, and the duration from admission to spontaneous closure was recorded. In our study, colonography would be arranged only after the flushing or drainage fluid was clear for several days.

\subsection{Replacement of PD with DLIST}

After admission, patients were treated with cefoperazone, and CT and colonography were performed. During imaging examinations, the length of the pus cavity and the position of the drainage tube were confirmed. In our study, immediate emergency surgery would be considered only if abdominal diffuse feces existed. Except for emergency surgery, the treatment process was as shown in Figure 2. In general, 
if the patient was asymptomatic (after using antibiotics, no systemic inflammatory response syndrome[SIRS]) after admission, replacement with DLIST would not be considered whether or not there was an isolated pus cavity or a pus cavity that could be contacted by the drainage tube. For patients with symptoms (with SIRS), there were three treatment courses. 1) If there was a pus cavity that could be reached by a drainage tube and there was no isolated pus cavity, replacement with DLIST was performed. 2) If there was not only a pus cavity that could be reached by a drainage tube but also an isolated pus cavity, replacement with DLIST was the first choice; if SIRS was still present within $48 \mathrm{~h}$ after the PD was replaced, a CT-guided puncture for isolated pus cavity the was planned. 3) If there was only an isolated pus cavity, replacement with DLIST was not performed, and instead a CT-guided puncture was performed. Antibiotics were stopped 5 days after the patient became asymptomatic.

Before the placement of DLIST, the shape of the drainage tube was evaluated by CT and sinography. During the process, the patient lay supine. After iodophor disinfection. A guide wire was insert in the abdomen via PD tube. PD was removed while the guide wire was in place. Seldinger method was used in the subsequent process. Use a skin expander to enlarge the sinus to the desired size then DLIST was inserted under the guidance of guide wire. A CT scan was then performed to confirm the position of the DLIST.

\subsection{Data analyses}

All statistical analyses were performed using SPSS 26.0 (IBM, Analytics, Armonk, NY). Mann-Whitney U tests were used to compare continuous variables across groups. Fisher exact tests were used to compare categorical variables. Kaplan-Meier estimates followed by a log-rank test and multivariate Cox regression analysis were used to compare the effects of different methods. A $P$ value of $<0.05$ was considered to indicate statistical significance.

\section{Results}

\subsection{Population}

From January 2011 to June 2020, a total of 153 patients with postoperative AL after rectal cancer surgery were transferred to our centers. Of these, eight patients with tumor metastasis during the treatment and 17 patients receiving emergency surgery immediately after admission were excluded from the study; thus, 128 patients were enrolled in our study (Figure 2).

The characteristics of the 128 patients are shown in Table 1. Of these, 76 patients underwent replacement of PD with DLIST and formed the DLIST group. The interval from admission to replacement was three days (Interquartile range [IQR]: 2-5 days). Another 52 patients did not have replacement of PD and formed the PD group. There were 38 (29.69\%) females, 23 in DLIST group (30.26\%) and 15 in PD group $(28.85 \%)(P=0.863)$. The median age was 64years (IQR: $58-66$ years) in the DLIST group and 59 years (IQR: $54-68$ years) in the PD group ( $P=0.242)$. The interval from cancer surgery to AL diagnosis was eight days (IQR: 7-9 days) in the DLIST group and eight days (IQR: 7-8 days) in the PD group $(P=0.394)$. 
Table 1

patients characteristics

\section{Clinical variables}

PD group

$(n=52)$

DLIST group $\quad p$ $(n=76)$

Female,No. (\%)

Age, years;(median,IQR )

BMI, kg/m2,(median,IQR )

Tumor stage,No. (\%)

IIA

IIB

IIC

IIIA

IIIB

IIIC

Perioperative radiotherapy,No. (\%)

Neoadjuvant therapy,No. (\%)

Dissected lymph nodes number $<12$,No. (\%)

Laparoscopic cancer surgery,No. (\%)

Interval from cancer surgery to AL diagnosed, day, (median,IQR )

Interval from AL diagnosed to admission, day, (median,IQR )

Length from anastomosis to anus , $\mathrm{cm}$, (means $\pm S D$ )

High ligation of the inferior mesenteric artery ,No. (\%)

lleostomy, No. (\%)

Puncture after admission, №. (\%)

Length of pus cavity $>5 \mathrm{~cm}$, No. (\%)

Hemoglobin, g/L, (median,IQR)

WBC*10^9/L, (median,IQR )
15(28.85)

23(30.26)

0.863

59(54-68)

21.2(21-

24.2)

64(58-66)

0.242

21.55(20-22.47)

0.589

0.140

3(3.95)

3(5.76)

16(30.77)

11(21.15)

16(30.77)

4(7.69)

1(1.92)

1(1.92)

2(3.85)

4(7.69)

3(5.76)

41(78.85)

8(7-8)

28.5(21-

36.75)

$6.34 \pm 3.91$

48(92.31)

41(78.85)

29(38.16)

8(15.38)

114(109-

123)

8.1(6.92-

13.57)
12(15.79)

12(15.79)

31(40.79)

10(13.16)

4(5.26)

4(5.26)

2(2.63)

1.000

9(11.84)

0.445

3(3.95)

0.686

60(78.95)

1.000

8(7-9)

0.394

20(18-25)

$<0.001$

0.108

70(92.10)

1.000

8(10.53)

$<0.001$

27(51.92)

0.123

48(63.16)

$<0.001$

109(100-117)

0.002

16(9.25-19)

$<0.001$
$7.49 \pm 3.99$ 


\begin{tabular}{|c|c|c|c|}
\hline Clinical variables & $\begin{array}{l}\text { PD group } \\
(n=52)\end{array}$ & $\begin{array}{l}\text { DLIST group } \\
(n=76)\end{array}$ & $\mathbf{p}$ \\
\hline Platelet*10^9/L, (median,IQR ) & $\begin{array}{l}298(209- \\
341)\end{array}$ & $\begin{array}{l}321(198- \\
485.25)\end{array}$ & 0.543 \\
\hline $\mathrm{CRP}, \mathrm{mg} / \mathrm{L}$, (means $\pm \mathrm{SD}$ ) & $49.63 \pm 43.23$ & $105.82 \pm 52.17$ & $<0.001$ \\
\hline $\mathrm{PCT}, \mathrm{ug} / \mathrm{L}$, (means $\pm S D)$ & $2.05 \pm 2.9$ & $4.66 \pm 3.08$ & $<0.001$ \\
\hline Alb, g/L, (median,IQR) & $31(28-36)$ & $28(26-32)$ & $<0.001$ \\
\hline Kidney injury,No. (\%) & $1(1.92)$ & $1(1.31)$ & 1.000 \\
\hline Hepatic injury,No. (\%) & $7(13.46)$ & $21(27.63)$ & 0.081 \\
\hline Respiratory function injury,No. (\%) & $1(1.92)$ & $3(3.95)$ & 0.639 \\
\hline cirrhosis,No. (\%) & $2(3.85)$ & $3(3.95)$ & 0.977 \\
\hline Diabetes mellitus,No. (\%) & $8(15.38)$ & $8(10.53)$ & 0.414 \\
\hline Smoking,No. (\%) & $13(25)$ & 15(19.73) & 0.479 \\
\hline $\begin{array}{l}\text { Interval from admission to replacement with AD, days, } \\
\text { (median,IQR) }\end{array}$ & - & $3(2-5)$ & -- \\
\hline
\end{tabular}

The interval from cancer surgery to diagnosis of $A L$ was $>30$ days for six patients, five of whom (2 PD, 3 DLIST) had protective end ileostomy closure during cancer surgery, and after ileostomy closure, the AL were diagnosed; the interval from cancer surgery to diagnosis of $A L$ was 108, 98, 99, 101, and 92 days. The remaining one patient without a protective ileostomy received postoperative radiotherapy, and the $\mathrm{AL}$ was diagnosed on the 169th day after cancer surgery. The interval from AL diagnosis to admission was 20 days (IQR: 18-25 days) in patients in DLIST group and 28.5 days (IQR: 21-36.75 days) in patients in PD group $(P<0.001)$.

On admission, patients in DLIST group had C-reactive protein (CRP) $(105.82 \pm 52.17 \mathrm{mg} / \mathrm{L}$ vs $49.63 \pm$ $43.23 \mathrm{mg} / \mathrm{L}, P<0.001)$, higher Procalcitonin(PCT) $(4.66 \pm 3.08 \mu \mathrm{g} / \mathrm{L}$ vs $2.05 \pm 2.9 \mu \mathrm{g} / \mathrm{L}, P=<0.001)$, higher white blood cells (WBC) $\left(16[9.25-19] \times 10^{9} / \mathrm{L}\right.$ vs $\left.8.1[6.92-13.57] \times 10^{9} / \mathrm{L}, P<0.001\right)$, and higher incidence of pus cavity length $>5 \mathrm{~cm}(48[63.16 \%]$ vs 8 [15.38\%], $P<0.001)$.

\section{2. lleostomy}

In our study, ileostomy was performed before admission in 49 patients (41 in PD group, eight in DLIST group). Of those patients, 28 patients had undergone protective ileostomy during cancer surgery (26 in PD group [nine with loop ileostomy and 17 with end ileostomy] and two in DLIST group [two with loop ileostomy ). The remaining 21 patients had emergency ileostomy (15 in PD group[four with loop ileostomy and 11 with end ileostomy]; six in DLIST group[four with loop ileostomy and two with end ileostomy]. The length from anastomosis to anus was $6.09 \pm 3.35 \mathrm{~cm}$ in the 49 patients $(6.57 \pm 4.36 \mathrm{~cm}$ in DLIST group vs. $6.09 \pm 3.03 \mathrm{~cm}$ in PD group, $p=0.825$ ). A total of 28 patients achieved spontaneous 
closure. The spontaneous closure rate was $62.5 \%$ (5/8) in patients with DLIST, and it was $51.12 \%(23 / 41)$ in patients with PD. The spontaneous closure time was 34 days (IQR: 30-40 days) in DLIST group and was 52 days (IQR:50-65days) in PD group $(\mathrm{p}<0.001)$.

\subsection{Primary outcome}

Spontaneous closure of AL was achieved in 67 (52.34\%) patients. There were 46 patients in DLIST group, for a spontaneous closure rate of $60.52 \%$, and 21 patients in PD group, for a spontaneous closure rate of 40.38\%. The median spontaneous closure time was 40days (IQR: 35-49days) in the DLIST group and 56 days (IQR: 50-76days) in the PD group. The unadjusted Cox regression analysis (HR $=2.155 ; 95 \% \mathrm{Cl}$ : 1.281-3.642; $P=0.004)$ and adjusted Cox regression analysis $(\mathrm{HR}=3.048 ; 95 \% \mathrm{Cl}: 1.787-5.197 ; \mathrm{P}<0.001)$ showed that DLIST was a positive factor for spontaneous closure (Table 2, Figure 3 ). In addition, length from anastomosis to anus (adjusted HR $=1.215 ; 95 \% \mathrm{Cl}$ : 1.012-1.369; $\mathrm{P}<0.001$ ) was also associated with spontaneous closure(Table 2). 
Table 2

univariable and multivariable cox- regression analysis of factors for spontaneous closure

\begin{tabular}{|c|c|c|c|c|c|c|}
\hline \multirow[t]{2}{*}{ Characteristic } & \multicolumn{3}{|c|}{$\begin{array}{l}\text { univariable regression } \\
\text { analysis }\end{array}$} & \multicolumn{3}{|c|}{$\begin{array}{l}\text { multivariable regression } \\
\text { analysis }\end{array}$} \\
\hline & HR & $95 \% \mathrm{Cl}$ & $\mathbf{p}$ & HR & $95 \% \mathrm{Cl}$ & $\mathbf{p}$ \\
\hline DLIST & 2.155 & $\begin{array}{l}1.281- \\
3.642\end{array}$ & 0.004 & 3.048 & $\begin{array}{l}1.787- \\
5.197\end{array}$ & $<0.001$ \\
\hline Female & 1.173 & $\begin{array}{l}0.754- \\
1.823\end{array}$ & 0.479 & & & \\
\hline Age & 0.983 & $\begin{array}{l}0.961- \\
1.006\end{array}$ & 0.123 & & & \\
\hline BMI & 1.059 & $\begin{array}{l}0.918- \\
1.221\end{array}$ & 0.432 & & & \\
\hline \multicolumn{7}{|l|}{ Tumor stage } \\
\hline I & Ref & - & - & & & \\
\hline IIA & 0.557 & $\begin{array}{l}0.221- \\
1.409\end{array}$ & 0.217 & & & \\
\hline IIB & 0.495 & $\begin{array}{l}0.192- \\
1.281\end{array}$ & 0.147 & & & \\
\hline IIC & 0.563 & $\begin{array}{l}0.234- \\
1.356\end{array}$ & 0.200 & & & \\
\hline IIIA & 0.856 & $\begin{array}{l}0.325- \\
2.258\end{array}$ & 0.754 & & & \\
\hline IIIB & 0.509 & $\begin{array}{l}0.127- \\
2.043\end{array}$ & 0.341 & & & \\
\hline IIIC & 1.785 & $\begin{array}{l}0.540- \\
5.896\end{array}$ & 0.342 & & & \\
\hline Perioperative radiotherapy & 0.045 & $\begin{array}{l}0.001- \\
2.675\end{array}$ & 0.137 & & & \\
\hline Neoadjuvant therapy & 0.823 & $\begin{array}{l}0.355- \\
1.905\end{array}$ & 0.649 & & & \\
\hline Dissected lymph nodes number $<12$ & 0.502 & $\begin{array}{l}0.159- \\
1.587\end{array}$ & 0.241 & & & \\
\hline Laparoscopic cancer surgery & 0.862 & $\begin{array}{l}0.577- \\
1.586\end{array}$ & 0.956 & & & \\
\hline $\begin{array}{l}\text { Interval from cancer surgery to AL } \\
\text { diagnosed }\end{array}$ & 0.985 & $\begin{array}{l}0.960- \\
1.011\end{array}$ & 0.248 & & & \\
\hline
\end{tabular}




\begin{tabular}{|c|c|c|c|c|c|c|}
\hline \multirow[t]{2}{*}{ Characteristic } & \multicolumn{3}{|c|}{$\begin{array}{l}\text { univariable regression } \\
\text { analysis }\end{array}$} & \multicolumn{3}{|c|}{$\begin{array}{l}\text { multivariable regression } \\
\text { analysis }\end{array}$} \\
\hline & HR & $95 \% \mathrm{Cl}$ & $\mathbf{p}$ & HR & $95 \% \mathrm{Cl}$ & $\mathbf{p}$ \\
\hline $\begin{array}{l}\text { Interval from AL diagnosed to } \\
\text { admission }\end{array}$ & 0.324 & $\begin{array}{l}0.963- \\
1.013\end{array}$ & 0.324 & & & \\
\hline Length from anastomosis to anus & 1.203 & $\begin{array}{l}1.089- \\
1.524\end{array}$ & $<0.001$ & 1.215 & $\begin{array}{l}1.012- \\
1.369\end{array}$ & $<0.001$ \\
\hline $\begin{array}{l}\text { High ligation of the inferior } \\
\text { mesenteric artery }\end{array}$ & 0.661 & $\begin{array}{l}0.262- \\
1.670\end{array}$ & 0.382 & & & \\
\hline Ileostomy before admission & 2.760 & $\begin{array}{l}0.767- \\
4.683\end{array}$ & 0.076 & & & \\
\hline Puncture after admission & 0.767 & $\begin{array}{l}0.461- \\
1.277\end{array}$ & 0.308 & & & \\
\hline Length of pus cavity $>5 \mathrm{~cm}$ & 0.841 & $\begin{array}{l}0.557- \\
1.270\end{array}$ & 0.411 & & & \\
\hline Hemoglobin & 1.011 & $\begin{array}{l}0.997- \\
1.026\end{array}$ & 0.133 & & & \\
\hline WBC & 0.990 & $\begin{array}{l}0.974- \\
1.007\end{array}$ & 0.255 & & & \\
\hline Platelet & 0.999 & $\begin{array}{l}0.997- \\
1.001\end{array}$ & 0.317 & & & \\
\hline CRP & 0.998 & $\begin{array}{l}0.995- \\
1.002\end{array}$ & 0.391 & & & \\
\hline РCT & 0.817 & $\begin{array}{l}0.519- \\
1.441\end{array}$ & 0.522 & & & \\
\hline Alb & 1.176 & $\begin{array}{l}0.487- \\
2.471\end{array}$ & 0.376 & & & \\
\hline Kidney injury & 0.637 & $\begin{array}{l}0.089- \\
4.571\end{array}$ & 0.653 & & & \\
\hline Hepatic injury & 0.832 & $\begin{array}{l}0.491- \\
1.410\end{array}$ & 0.495 & & & \\
\hline Respiratory function injury & 0.178 & $\begin{array}{l}0.036- \\
1.854\end{array}$ & 0.258 & & & \\
\hline cirrhosis & 0.779 & $\begin{array}{l}0.246- \\
2.461\end{array}$ & 0.670 & & & \\
\hline Diabetes mellitus & 0.460 & $\begin{array}{l}0.213^{-} \\
0.996\end{array}$ & 0.049 & 0.594 & $\begin{array}{l}0.255- \\
1.387\end{array}$ & 0.229 \\
\hline Smoking & 0.662 & $\begin{array}{l}0.385- \\
1.137\end{array}$ & 0.135 & & & \\
\hline
\end{tabular}




\subsection{Secondary outcomes}

The LOS was 54 days (IQR: $41.25-117$ days) in the DLIST group and 112 days (IQR: $66.75-127.75$ days) in the PD group. Kaplan-Meier analysis showed that the patients in DLIST group had a shorter LOS $(P=$ 0.005 , Figure 4A). In addition, adjusted Cox regression analysis showed that replacement of PD (HR = 2.893; $95 \% \mathrm{Cl}: 2.943-5.135 ; P<0.001)$ had a positive influence on reducing LOS. In the 67 patients with spontaneous closure, the LOS of the DLIST group was shorter (Kaplan-Meier, $P<0.001$, Figure 4B), However, in the 61 patients without spontaneous closure, the LOS was comparable between the two groups (Kaplan-Meier, $P=0.228$, Figure 4C).

The median hospitalization expense was $\$ 18,721$ (IQR: $\$ 14,982-44,960$ ) in the DLIST group and $\$ 40,840$ (IQR: $\$ 20,932-50,529)$ in the PD group $(P<0.001)$. The hospitalization expense for patients with spontaneous closure was lower in DLIST group (\$15,981 [IQR: \$13,987-17,912] vs. \$20,932 [IQR: \$18,41222,981]; $P<0.001$ ), while it was comparable between the two groups in patients without spontaneous closure (\$48,293 [IQR: \$44,764-51,739] vs. \$49,723 [IQR: \$44,872-50,982]; $P=0.942)$.

\subsection{Definitive surgery for AL}

All 61 patients without spontaneous closure received definitive surgery for AL. Within a week before definitive surgery for $A L, a C T$ scan was performed, and $A L$ was evaluated again. The reduction of the length of the pus cavity was significant in the DLIST group $(6.64 \pm 3.18 \mathrm{~cm}$ on admission vs. $1.57 \pm 0.67$ $\mathrm{cm}$ before definitive surgery, $P<0.001)$. Of the 31 patients receiving definitive surgery in the PD group, 10 patients had a pus cavity that could be reached by the drainage tube. The length of the pus cavity on admission was comparable with that before definitive surgery $(1.61 \pm 0.70 \mathrm{~cm}$ on admission vs $1.53 \pm$ $0.58 \mathrm{~cm}$ before definitive surgery, $P=0.682$ ). Among the 61 patients without spontaneous closure, the definitive surgery was showed in Table 3. 
Table 3

Definitive surgery for AL

\begin{tabular}{|lll|}
\hline & DLIST group & PD group \\
\hline Number & 30 & 31 \\
\hline Characteristics,No & & \\
\hline No ileostomy & 27 & 13 \\
\hline With ileostomy before admission & 3 & 18 \\
\hline Surgical process,No & & \\
\hline AL resection & & \\
\hline AL resection only & 7 & 4 \\
\hline AL resection+ileostomy closure & 0 & 4 \\
\hline Colostomy & 20 & 14 \\
\hline Colostomy+closure of ileostomy & 3 & 9 \\
\hline
\end{tabular}

\section{Discussion}

According to the International Study Group of Rectal Cancer [14], AL after radical resection of colorectal cancer can be classified as grade $A, B$, or $C$. Grade $C A L$ is generally the most serious, requiring emergency surgery. It seemed that once the AL occurred, the consequences would be serious, and most colorectal $\mathrm{AL}$ was grade C. According to a review, the incidence of grade C AL was approximate $60 \%$ in patients with $A L[15]$. In fact, grade $C A L$ or incidence of emergency surgery for AL might be higher. For instance, in a national study in Denmark, emergency surgery was performed at rates as high as $85 \%$ in AL cases[16]. In addition, in a study performed in Laval University, $73 \%$ of $A L$ cases were grade $C$ in patients without a protective stoma[9]. As a result, the treatment of $A L$ after colorectal surgery was mainly focused on the emergency surgery. The main objective of emergency surgery for AL was to achieve source control. In our experience, using the DLIST tube seemed to be a useful method to establish source control. In our previous study[12], the DLIST was placed in the study group during radical resection of rectal cancer, and it was shown that emergency surgery was necessary in only $15 \%$ of ALs, while $60 \%$ of ALs required emergency surgery in the control group. In addition, in another of our reports[17], more than $2000 \mathrm{ml}$ of colonic fluid and pus could be drained out within 48 hours using the DLIST. Thanks to the design of the DLIST, continuous irrigation can thin out the thick colonic fluid and make it easier to drain. We have made full use of DLIST through washing and irrigation to remove the infections. This may be one of the mechanisms leading to the pus cavity shrinkage .

In our study, it was shown that spontaneous closure was associated with the placement of DLIST after AL occurred. In addition to the adequate drainage and removal of contaminants, the result seemed to be 
associated with the influence of negative pressure on granulation tissue. The obvious and common manifestation of this influence is that significant shrinkage of the wound can be observed as the edge of the granulation would deform and contract under the negative pressure[18]. Furthermore, negative pressure therapy can clear white blood cells and inflammatory factors[19] and stimulate cellular proliferation, angiogenesis, and the formation of granulation tissue[20] of the granuloma. In our study, the DLIST tube was used to provide negative pressure after insertion into the pus cavity. The effect of the negative pressure was to improve the filling of granulation tissue into the pus cavity and resolve the leakage. The direct reactions in our present research were the obvious shrinkage of the pus cavity and the higher incidence of spontaneous closure in the DLIST group compared with the PD group. In recent years, researchers have tried to treat rectal AL using innovative drainage methods and have achieved good clinical outcomes in a few selected patients $[9,10]$. However, the rates were variable in different studies[21]. A Swedish study investigating a certain number of patients[11], showed that the general spontaneous closure rate seemed to be only about $50 \%-60 \%$ when using the EVAC and transanal irrigation. In theory, EVAC microstructure could have a better effect on forming granulation tissue and promoting granulation tissue shrinkage[18]. In our previous study[13], this was demonstrated to be true. After all, the special sponge tissue with its small holes can fill the whole pus cavity and distribute pressure evenly to the cavity wall. However, what cannot be ignored is that the larger diameter holes in the tubes allow thick infections to be removed more easily compared with the vacuum-assisted closure system. In addition, removal of the infection was another important factor for spontaneous closure. This may be why EVAC seemed to have no obvious advantage compared with transanal drainage in Weréen's study[11]. In our study, the spontaneous closure rate was about $60 \%$ when using DLIST. The opposing views might be that DLIST did not improve the spontaneous closure rate very significantly, compared with transanal drainage and vacuum-assisted closure system. However, it should be noted that in the previous studies focused on the two methods, most patients received a stoma. In our studies, only a small number of patients had stoma. In general, compared with EVAC, DLIST might be better in clearing the thick infection, thanks to continuous irrigation of normal saline and negative pressure and forming granulation tissue. However, it was difficult to distinguish the best drainage method according to the existing research. As a result, future randomized clinical trials are necessary.

There were limitations in our study. The first limitation is that the study was retrospectively performed in two centers using similar treatments. So, selection bias was likely present. The second limitation is that the spontaneous closure was diagnosed only after colonography confirmation. As a result, we thought that diagnosis was often not timely, which might lead to bias. The third limitation is that as transferred from different units the overall number of operated cases and percentage of AL unfortunately is not possible. The fourth limitation is that the endoscopy-related information was lacking. Mucosal inflammation (with ulcers, erosion, and so on) may influence spontaneous closure time, so information regarding mucosal inflammation should be collected in future studies. In addition, our experience indicates that perioperative radiotherapy may be a very important factor for the failure of spontaneous closure. (In the present study, only four patients had perioperative radiotherapy, and spontaneous closure was not achieved in all four). However, in the present study, we could not conclude from the regression 
results that postoperative radiotherapy was associated with spontaneous closure. The main reason might be that the number of patients with perioperative radiotherapy was so small (four patients). Future studies should focus on this potential factor. An other limitation was that the general situation of patients in DLIST group was worse. However, we have to understand that a group of patients with worse baseline data can achieve better efficacy. It seemed to be a more favorable proof.

In addition, it might be that patients receiving the standard of care, namely surgery with end colostomy or creation of a protective ileostomy for quick and effective control. We grant that surgical control of the source of infection is more direct, faster, and more thorough than all drainage methods. Actually, symptomatic patients always had a purulent cavity and poor drainage. Patients with AL should of course undergo laparotomy at an early stage. In addition, if there was a source of infection accumulating near the AL, the operation required not only devascularization but also debridement around the AL. As a result, simple ileostomy may not solve the problem quickly. In other words, patients might still be symptomatic after ileostomy if the drainage mode did not change. The perfect operation should be take-down anastomosis plus colostomy. However, the interval from AL diagnosis to admission was 20 (18-25) days in the DLIST group. It meant that the adhesion had gradually formed, and the surgery might cause secondary injury around the leakage. We used to attempt the surgical control in very early years, but in some patients, the AL cannot be exposed well. We had to perform colostomy in a hurry, and eventually we had a distal colonic stump fistula in addition to the unresolved AL. We feel that one should be cautious about laparotomy in patients with abdominal infection following leakage one month after the first operation, because it is like a trap. The early devascularization is a good method, but sometimes it might be risky to expose the AL during surgery. As a result, when considering the complications of the surgical control, we chose to place the DLIST as often as possible for irrigation and drainage.

\section{Conclusion}

Placing a DLIST is an effective method to treat AL following rectal cancer surgery. Compare with PD, the cost of DLIST for treatment of AL is lower, and the length of stay is shorter.

\section{Abbreviations}

$\mathrm{AL}=$ Anastomotic leakages;

$\mathrm{CRP}=\mathrm{C}$-reactive protein;

DLIST=Double-lumen irrigation-suction tubes;

EVAC=Endoscopic vacuum-assisted closure;

ISGRC=International Study Group of Rectal Cancer;

LOS=length of stay;

Page 13/21 
PCT=Procalcitonin;

$\mathrm{PD}=$ passive drainage;

SIRS=systemic inflammatory response syndrome;

White blood cells=WBC.

\section{Declarations}

\section{Ethics approval and consent to participate:}

The protocol for this research project has been approved by Committee of Jinling Hospital, Approval No. NJZY-21-04-0161, and .Committee of Jinling Hospital, Approval No. JNYY-10623. All subjects provided signed informed consent. All methods were carried out in accordance with relevant guidelines and regulations.

\section{Consent for publication:}

Not applicable

\section{Availability of data and materials:}

The datasets used and/or analysed during the current study available from the corresponding author on reasonable request.

\section{Competing interests:}

The authors declare that they have no competing interests.

\section{Funding:}

None

\section{Authors' contributions:}

Risheng Zhao and Weiliang Tian provide research objects. Xin Xu; Zheng Yao and Risheng Zhao collected and analysed the data; Zheng Yao; Ming Huang and Weiliang Tian wrote the main manuscript text; Xin $\mathrm{Xu}$, prepared figures. Zheng Yao designed the research. Zheng Yao was the correspondence author. Weiliang Tian revised the manuscript. Ming Huang and Weiliang Tian were the first authors. 


\section{Acknowledgements:}

Not applicable

\section{References}

1. Dhayat S, Senninger N. Predictors for Anastomotic Leak After Colorectal Resection. Ann Surg. 2015;261(6):e155. doi:10.1097/SLA.0000000000000458.

2. Tjandra JJ, Kilkenny JW, Buie WD, et al. Practice parameters for the management of rectal cancer (revised). Dis Colon Rectum. 2005;48(3):411-423. doi:10.1007/s10350-004-0937-9.

3. Matthiessen P, Hallböök O, Rutegård J, Simert G, Sjödahl R. Defunctioning stoma reduces symptomatic anastomotic leakage after low anterior resection of the rectum for cancer: a randomized multicenter trial. Ann Surg. 2007;246(2):207-214. doi:10.1097/SLA.0b013e3180603024.

4. Fazio VW, Zutshi M, Remzi FH, et al. A randomized multicenter trial to compare long-term functional outcome, quality of life, and complications of surgical procedures for low rectal cancers. Ann Surg. 2007;246(3):481-490. doi:10.1097/SLA.0b013e3181485617.

5. Ptok H, Steinert R, Meyer F, et al. Operative Behandlung von Rektumkarzinomen im Vergleich. Onkologische Langzeitergebnisse einer multizentrischen Beobachtungsstudie nach laparoskopischassistierter, konvertierter und primär offener Operation [Long-term oncological results after laparoscopic, converted and primary open procedures for rectal carcinoma. Results of a multicenter observational study]. Chirurg. 2006;77(8):709-717. doi:10.1007/s00104-006-1199-y.

6. Veenhof AA, Kropman RH, Engel AF, et al. Preoperative radiation therapy for locally advanced rectal cancer: a comparison between two different time intervals to surgery. Int $\mathrm{J}$ Colorectal Dis. 2007;22(5):507-513. doi:10.1007/s00384-006-0195-5.

7. Lindgren R, Hallböök $\mathrm{O}$, Rutegård J, Sjödahl R, Matthiessen P. What is the risk for a permanent stoma after low anterior resection of the rectum for cancer? A six-year follow-up of a multicenter trial. Dis Colon Rectum. 2011;54(1):41-47. doi:10.1007/DCR.0b013e3181fd2948.

8. Jutesten $\mathrm{H}$, Draus J, Frey $\mathrm{J}$, et al. High risk of permanent stoma after anastomotic leakage in anterior resection for rectal cancer. Colorectal Dis. 2019;21(2):174-182. doi:10.1111/codi.14469.

9. Sirois-Giguère E, Boulanger-Gobeil C, Bouchard A, et al. Transanal drainage to treat anastomotic leaks after low anterior resection for rectal cancer: a valuable option. Dis Colon Rectum. 2013;56(5):586-592.doi:10.1097/DCR.0b013e31827687a4

10. Weidenhagen R, Gruetzner KU, Wiecken T, Spelsberg F, Jauch KW. Endoscopic vacuum-assisted closure of anastomotic leakage following anterior resection of the rectum: a new method. Surg Endosc. 2008;22(8):1818-1825. doi:10.1007/s00464-007-9706-x

11. Weréen A, Dahlberg M, Heinius G, et al. Long-Term Results after Anastomotic Leakage following Rectal Cancer Surgery: A Comparison of Treatment with Endo-Sponge and Transanal Irrigation. Dig Surg. 2020;37(6):456-462. doi:10.1159/000508935 
12. Yang $F$, Liu $D, X u X$, et al. A double-lumen irrigation-suction tube placed during operation could reduce the risk of grade $\mathrm{C}$ anastomotic leakage resulting from selective rectal colon cancer radical resection. Langenbecks Arch Surg. 2020;405(7):1007-1016. doi:10.1007/s00423-020-01959-z

13. Yao Z, Tian W, Xu X, et al. The Double-Lumen Irrigation-Suction Tube in The Management of Incisional Surgical Site Infection After Enterocutaneous Fistula Excisions: An Observational Study [published online ahead of print, 2019 Dec 4]. J Invest Surg. 2019;1-7. doi:10.1080/08941939.2019.1693667

14. Rahbari NN, Weitz J, Hohenberger W, et al. Definition and grading of anastomotic leakage following anterior resection of the rectum: a proposal by the International Study Group of Rectal Cancer. Surgery. 2010;147(3):339-351. doi:10.1016/j.surg.2009.10.012

15. Cong ZJ, Hu LH, Bian ZQ, et al. Systematic review of anastomotic leakage rate according to an international grading system following anterior resection for rectal cancer. PLoS One. 2013;8(9):e75519. Published 2013 Sep 25. doi:10.1371/journal.pone.0075519

16. Krarup PM, Jorgensen LN, Harling H; Danish Colorectal Cancer Group. Management of anastomotic leakage in a nationwide cohort of colonic cancer patients. J Am Coll Surg. 2014;218(5):940-949. doi:10.1016/j.jamcollsurg.2014.01.051

17. Yao Z, Tian $W, X u X$, et al. An innovative method for placing a double-lumen irrigation-suction tube in the management of abdominal infection: A case report. Medicine (Baltimore). 2018;97(9):e0048. doi:10.1097/MD.0000000000010048

18. Huang C, Leavitt T, Bayer LR, Orgill DP. Effect of negative pressure wound therapy on wound healing. Curr Probl Surg. 2014;51(7):301-331. doi:10.1067/j.cpsurg.2014.04.001

19. Nuutila K, Siltanen A, Peura M, et al. Gene expression profiling of negative-pressure-treated skin graft donor site wounds. Burns. 2013;39(4):687-693. doi:10.1016/j.burns.2012.09.014

20. Erba $\mathrm{P}$, Ogawa R, Ackermann $\mathrm{M}$, et al. Angiogenesis in wounds treated by microdeformational wound therapy. Ann Surg. 2011;253(2):402-409. doi:10.1097/SLA.0b013e31820563a8

21. Strangio G, Zullo A, Ferrara EC, et al. Endo-sponge therapy for management of anastomotic leakages after colorectal surgery: A case series and review of literature. Dig Liver Dis. 2015;47(6):465-469. doi:10.1016/j.dld.2015.02.007

\section{Figures}




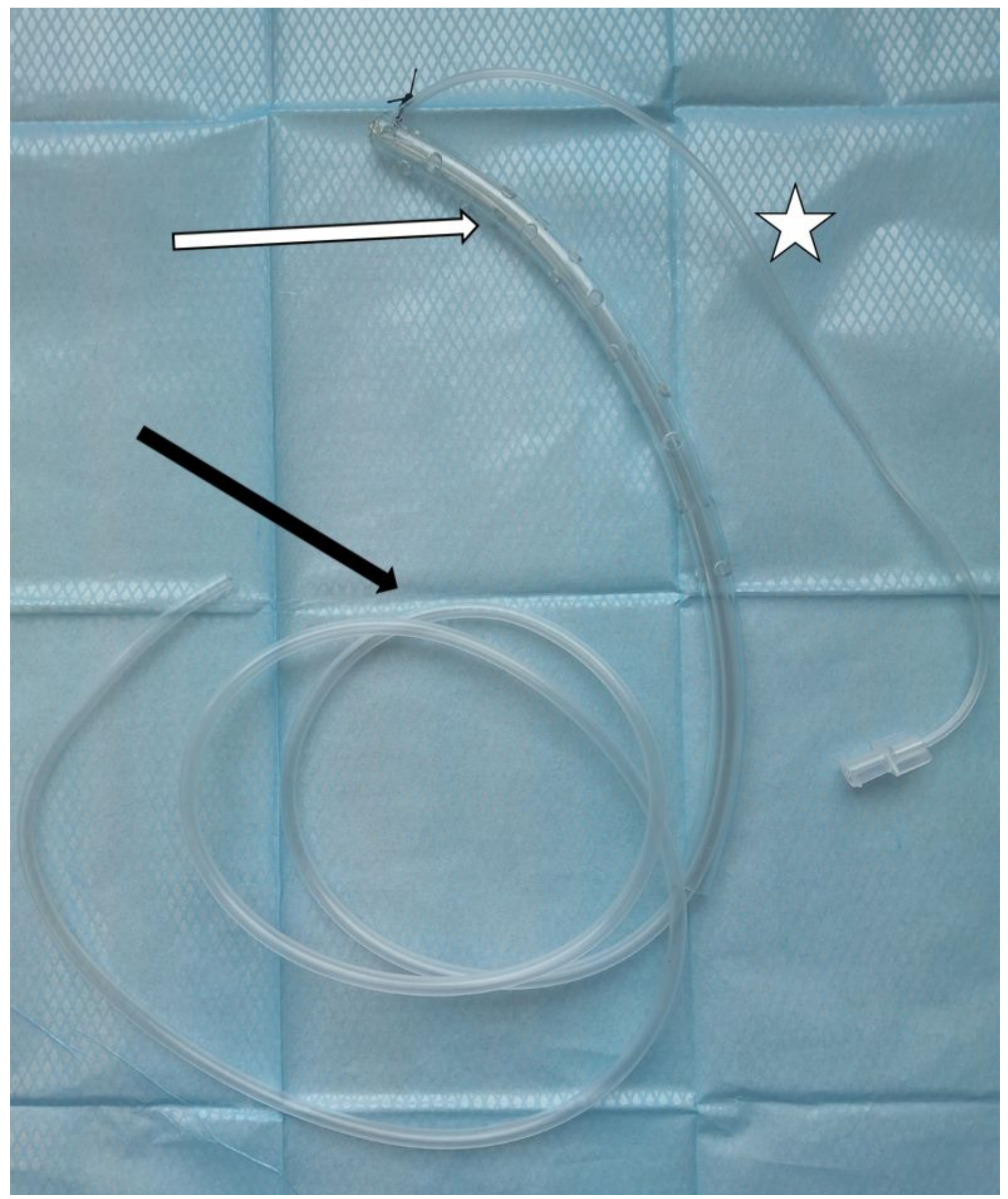

\section{Figure 1}

Double-lumen irrigation-suction tube consist of irrigation catheter ( ), suction catheter (identified by black arrow), and end-closed supporting pipe which was riddled with holes with diameter of about $3 \mathrm{~mm}$ (the distance between each hole is about $1 \mathrm{~cm}$, identified by white arrow). 


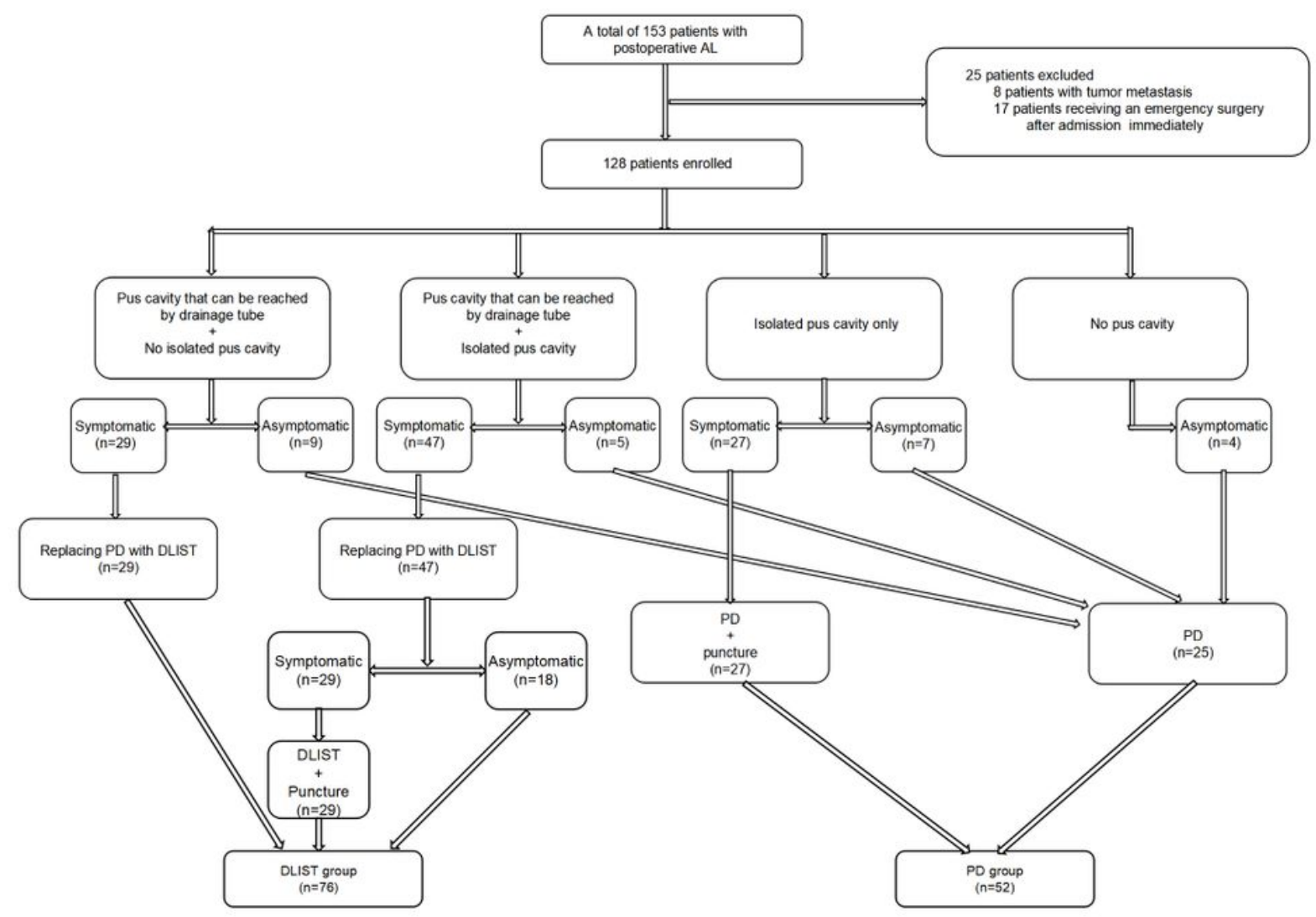

Figure 2

A total of 153 patients with postoperative AL after rectal cancer surgery were transferred to our centers. Of these, 8 patients with tumor metastasis during the treatment and 17 patients receiving emergency surgery immediately after admission were excluded from the study; thus, 128 patients were enrolled in our study. According to whether or not the passive drainage placed during the rectal cancer surgery was replaced with the DLIST, patients were divided into a passive drainage (PD) group and a double-lumen irrigation-suction tube (DLIST) group. 


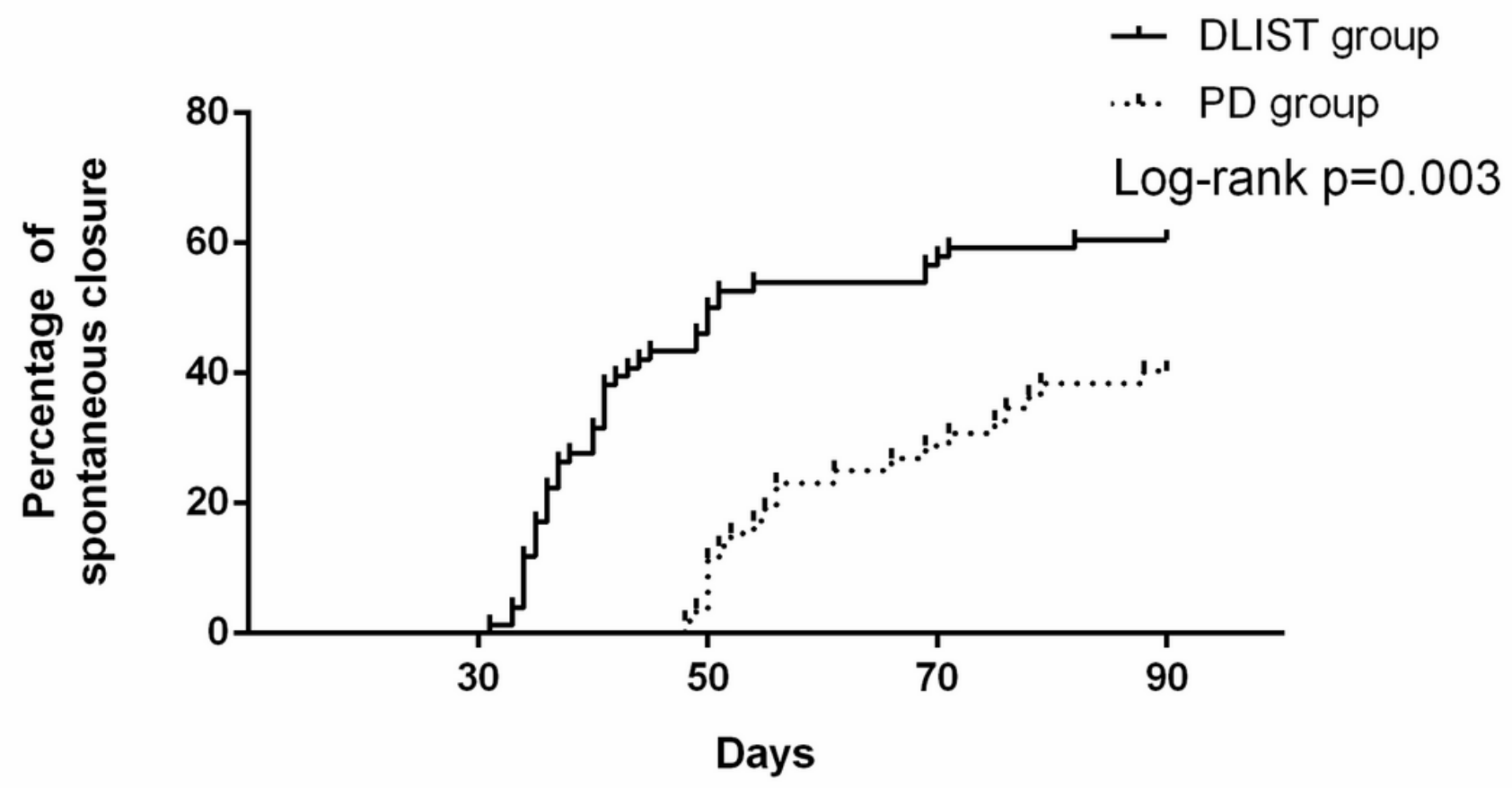

Numbers at risk

DLIST group

PD group
00

00
02

00
37

05
44

15
46

21

\section{Figure 3}

There were 46 patients in DLIST group, for a spontaneous closure rate of $60.52 \%$, and 21 patients in PD group, for a spontaneous closure rate of $40.38 \%$. 

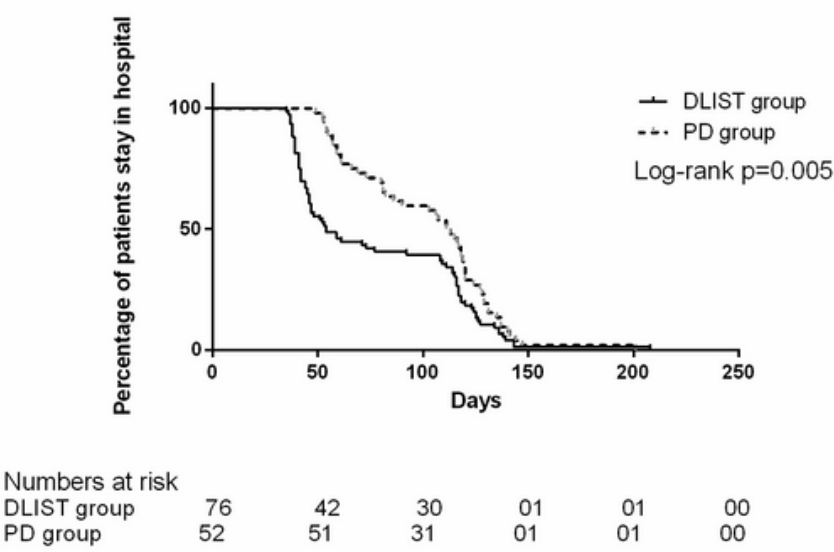

B
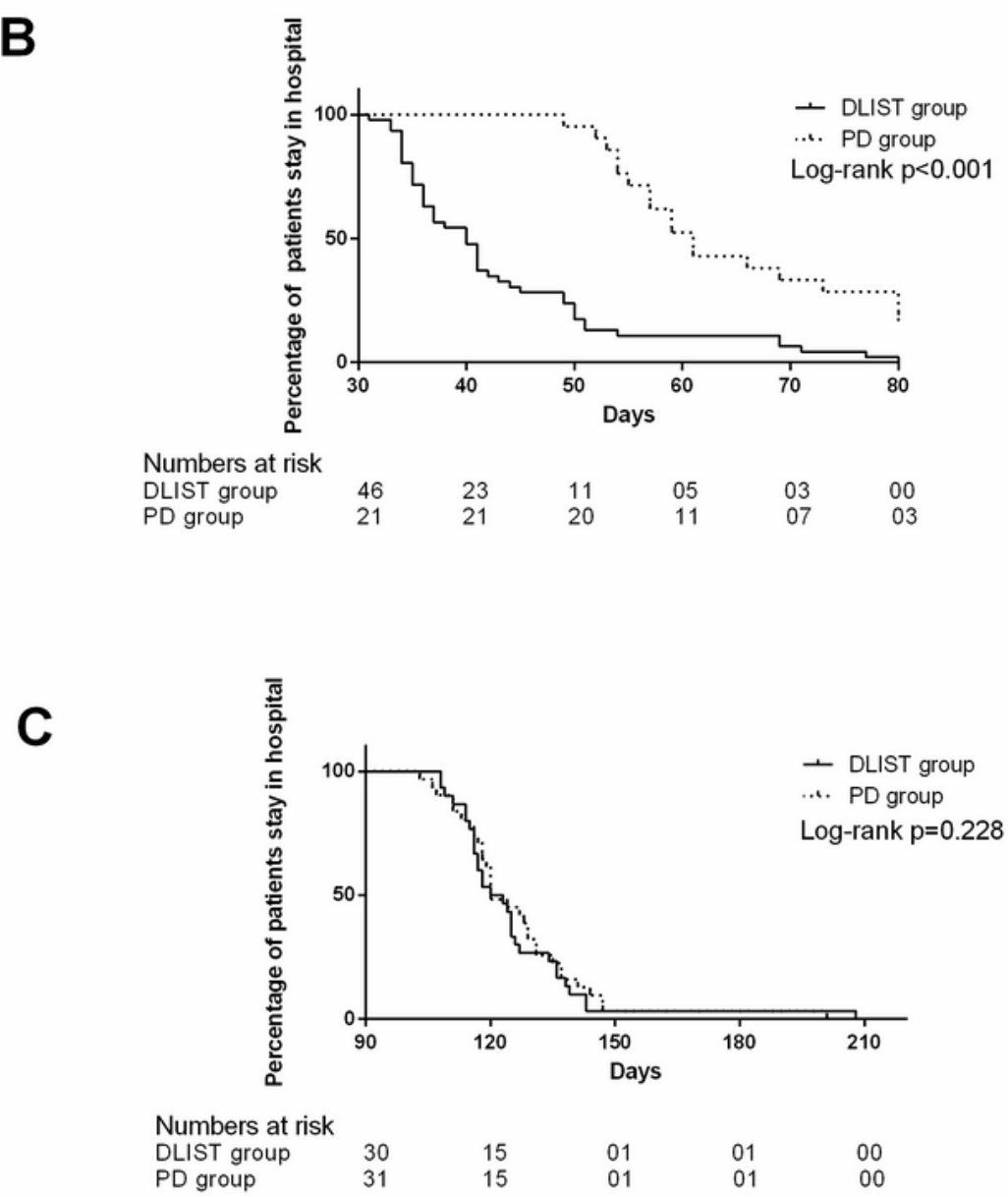

\section{Figure 4}

Kaplan-Meier analysis showed that the patients in DLIST group had a shorter LOS ( $P=0.005$, Figure 4A). In addition, adjusted Cox regression analysis showed that replacement of PD (HR $=2.893 ; 95 \%$ Cl: 2.943$5.135 ; \mathrm{P}<0.001$ ) had a positive influence on reducing LOS. In the 67 patients with spontaneous closure, the LOS of the DLIST group was shorter (Kaplan-Meier, $\mathrm{P}<0.001$, Figure 4B), However, in the 61 patients 
without spontaneous closure, the LOS was comparable between the two groups (Kaplan-Meier, $\mathrm{P}=0.228$, Figure 4C). 